\title{
Building Accessible Cyberinfrastructure in the Global Disability Community: Evaluating Collaboration Readiness and Use of the DID Policy Collaboratory
}

\author{
Derrick L. Cogburn \\ American University \\ dcogburn@american.edu
}

\author{
Filippo Trevisan \\ American University \\ trevisan@american.edu
}

\author{
Erin Spaniol \\ American University \\ erin.spaniol@idppglobal.org
}

\author{
Maya C. Aguilar \\ American University \\ maguilar@american.edu
}

\begin{abstract}
This study is focused on better understanding the socio-technical infrastructure required to enhance participation of the global disability community in key global governance processes. It explores the impact of a virtual organizational platform, called the Disability Inclusive Development (DID) Policy Collaboratory on the participation of the UN Disability Inclusive and Accessible Urban Development (DIAUD) Network in the preparatory processes for the UN Habitat III Conference. This paper asks four broad questions about the DIAUD network: (1) what is its origin, composition, and structure; (2) to what degree does it represent a transnational advocacy network; (3); what is its baseline "collaboration readiness"; and (4) how effectively does it use the Collaboratory? Data are drawn from surveys and participant observation at virtual and face-to-face network meetings. Key findings include: (1) DIAUD is organized as a TAN; (2) has important linkages with epistemic communities; and (3) has made substantive and sustained policy contributions.
\end{abstract}

\section{Introduction}

The global community is facing an historic moment for inclusive social and economic development. Fueled by technological advances and socio-political changes at the United Nations, there is an important confluence of several international development and human rights initiatives, including the Convention on the Rights of Persons with Disabilities (CRPD), the 2030 Agenda for Sustainable Development (SDGs) and the HighLevel Political Forum (HLPF); UN Habitat III and the New Urban Agenda (NUA); the World Summit on the Information Society (WSIS+10) Review, and the Internet Governance Forum (IGF).
These initiatives also present opportunities for persons with disabilities, who make up approximately fifteen percent of every country's population [47], to become more involved in the deliberations, decision-making, follow-up, implementation, and monitoring processes of these major global initiatives and the "global governance" processes they represent.

Take for example, the $9^{\text {th }}$ Conference of States Parties (COSP) to the CRPD, held 13-15 June 2016 at United Nations Headquarters in New York City. The theme for COSP-9 was "Implementing the 2030 development agenda for all persons with disabilities: Leaving no one behind". Similarly, the theme for the inaugural 2016 High-Level Political Forum (HLPF) for the SDGs held from 11-20 July 2016 was "Ensuring that No One is Left Behind." The overall theme for Habit III, scheduled for Quito, Ecuador from 17-20 October is the New Urban Agenda. Finally, the focus of the WSIS+10 Outcome Document is the use of the Internet and ICTs to support the implementation of the new Sustainable Development Agenda.

This convergence of initiatives presents an opportunity to advance the goals of more than 1 billion persons with disabilities around the world for a more inclusive global community that supports their social, political, and economic rights. However, previous research has identified numerous challenges to enhancing the active and effective participation of persons with disabilities in global governance processes [39, 40, 49].

\section{Purpose}

The purpose of this study is to better understand the socio-technical infrastructure that might enhance the participation of persons with disabilities and the global disability community in the multiple and complex national, regional, and international processes of global governance; and to develop a 
prototype virtual organization called the DisabilityInclusive Development (DID) Policy Collaboratory which is accessible to persons with disabilities. This study will focus on the UN network on Disability Inclusion and Accessible Urban Development (DIAUD), as they attempt to use the DID Policy Collaboratory to participate in the processes for the UN conference on Housing and Sustainable Urban Development (Habitat III).

The study will enable a deeper understanding of the impact accessible cyberinfrastructure can have on the participation of persons with disabilities, the global disability community, and broader constituencies in global governance processes.

\section{Conceptual Framework}

Since the founding of the UN, finding ways for citizens to be involved in its work has been a key objective. Numerous attempts have been made to enhance this involvement, but the concept of a Transnational Advocacy Network (TAN) holds great promise. TANs are defined as "networks of activists, distinguishable largely by the centrality of principled ideas or values in motivating their formation" [48]. These TANs are expected to have a collection of participants working internationally on policy issue(s) who have: (1) shared values; (2) a common discourse; (3) a dense exchange of information; and (4) who seek to influence policy [48].

In addition, three key components characterize a TAN [48]:

(1) Networked Organizational Form: "forms of organization characterized by voluntary, reciprocal, and horizontal patterns of communication and exchange."

(2) Advocacy-Based: "plead the cause of others or defend a cause or proposition." These networks are organized to promote causes, principled ideas, and norms, and they often involve individuals advocating policy changes that cannot be easily linked to a rationalist understanding of their 'interests'."

(3) Transnational in Scope: Not limited to any one country, but are fluid between domestic and international realms, "it stresses fluid and open relations among committed and knowledgeable actors working in specialized issue areas."

In addition, a TAN can include any combination of the following types of actors, with heavy emphasis on the first category [48]:

(1) International and domestic nongovernmental research and advocacy organizations;

(2) Local social movements;
(3) Foundations;

(4) The media;

(5) Churches, trade unions, consumer organizations, and intellectuals;

(6) Parts of regional and international intergovernmental organizations; and

(7) Parts of the executive and/or parliamentary branches of government (adapted from [48, p. 9].

While a great deal has been written subsequently about these types of networks, this seminal definition is still helpful in specifying how we understand a TAN. In our work, we are particularly interested in how TANs engage in $\mathrm{UN}$ conferences, meetings, and events.

\section{Research Questions}

This paper is part of a larger project on accessible global governance led by the American University Institute on Disability and Public Policy and supported by The Nippon Foundation. It asks four grand tour questions: (1) What is the evolution and structure of the DIAUD network?; (2) To what degree does the DIAUD network reflect the model of a Transnational Advocacy Network; (3) What is the level of "Collaboration Readiness" within the DIAUD network; and (4) How has the DIAUD network used the cyberinfrastructure of the Disability-Inclusive (DID) Policy Collaboratory? Each of these broad questions has several specific, operationalized research questions. The complete structure of the research questions for this study is below:

RQ1: What is the evolution and structure of the DIAUD network?

RQ1.1 How was the DIAUD Network created?

RQ1.2 What key organizations and people comprise the DIAUD Network?

RQ1.3 What types of actors comprise the DIAUD Network?

RQ1.4 What regions comprise the DIAUD Network?

RQ1.5 Which DIAUD Network members have been most active in the DIAUD Network as represented by their frequency of posting on the mailing list?

RQ1.6 Which DIAUD Network members have been most influential in the DIAUD Network as represented by the frequency of responses on the mailing list?

RQ1.7 How has the membership, participation and structure of the DIAUD Network changed over time? 
RQ2: To what degree does the DIAUD Network reflect the model of a Transnational Advocacy Network (TAN)?

RQ2.1 Does the DIAUD Network have shared values?

RQ2.2 Does the DIAUD Network have a common discourse?

RQ2.3 To what degree does the DIAUD Network have a dense exchange of information?

RQ2.4 To what degree does the DIAUD Network seek to influence policy?

RQ2.5 Are there any clear linkages between the DIAUD Network and an epistemic community?

RQ3: What is the level of "Collaboration Readiness" within the DIAUD network?

RQ3.1 What are the current levels of communication within the DIAUD network?

RQ3.2 What are the current levels of trust within the DIAUD network?

RQ3.3 What are the current levels of social network centrality within the DIAUD network?

RQ3.4 What is the degree of Leadership Preference/Perception Alignment within the DIAUD network?

RQ3.5 What factors best predict "Collaboration Readiness" within the DIAUD network?

RQ4: How has the DIAUD network used the cyberinfrastructure of the DID Policy Collaboratory?

RQ4.1 To what degree have the DIAUD network members accessed the People-to-People resources of the DID Collaboratory?

RQ4.2 To what degree have the DIAUD network members accessed the People-to-Resources aspects of the DID Collaboratory?

RQ4.3 To what degree have the DIAUD network members accessed the People-to-Facilities resources of the DID Collaboratory?

RQ4.4 To what degree has the DIAUD network participated in drafting recommendations to Habitat III?

\section{Methodology}

This project aims to use the accumulated wisdom, best practices and lessons learned from our decades of work building accessible virtual organizations, global virtual teams, cyberinfrastructure, and cyberlearning environments to address the challenges inherent in facilitating more effective participation of persons with disabilities, and the global disability community, in the global governance processes represented by each of these important United Nations initiatives.
The project has three major phases between 1 June 2016 and 31 May 2017. Phase One focuses on the rapid prototyping and development of the Disability Inclusive Development (DID) Policy Collaboratory, with the goal of serving as a platform to support various networks within the global disability community to engage more effectively in specific UN conferences, meetings and events. While the DID Collaboratory is designed to support multiple networks, this phase of the study is focusing on supporting the Global Multistakeholder Network on Disability Inclusion and Accessible Urban Development (DIAUD). Members of the DIAUD Network were appointed by the United Nations Department of Economic and Social Affairs (UNDESA), specifically the Secretariat for the Convention on the Rights of Persons with Disabilities (CRPD) and the Division of Social Policy and Development (DSPD). The DIAUD Network is focused on developing and integrating disabilityinclusive development contributions into the New Urban Agenda (NUA) and outcome document for the United Nations Conference on Housing and Sustainable Urban Development (Habitat III), taking place in Quito, Ecuador, 17-20 October 2016.

We developed and administered a web-based baseline survey $\left(\mathrm{O}^{1}\right)$ of all DIAUD Network participants $(\mathrm{N}=55)$ in May 2016, with a planned follow-up survey $\left(\mathrm{O}^{2}\right)$ after Habitat III in October. The survey has 85 total items, dived into six sections, which are: (1) Demographic Information; (2) Participation in UN Conferences; (3) Participation in non-UN conferences; (4) Collaboration within the DIAUD Network; (5) Experience with ICTs; and (6) Trust and Social Capital. We have also administered the baseline survey to a control group of the global disability community not participating in the DID Collaboratory. Our response rate was close to $50 \%$ $(\mathrm{n}=20)$.

After the baseline data collection, we began building the prototype cyberinfrastructure for the DID Collaboratory (disabilityinclusivedevelopment.net) and introduced the DIAUD Network to its components.

While the specific components of the cyberinfrastructure are dynamic and are changed, based on usage patterns and feedback from the network, it currently includes the following broad categories of social and technical resources: (1) People-to-People, such as photo directories of members and constituent relationship management (CRM) services; (2) People-to-Resources, such as background resources, paper archives, and document repositories; and (3) People-to-Facilities, such as synchronous accessible audio-video webconferencing and application sharing. 
In Phase Two, the project broadens participation in the DID Collaboratory to support other networks and working groups engaged in related global governance initiatives described above. Formative evaluation will facilitate iterative development of the socio-technical infrastructure of the collaboratory.

Phase Three of the project focuses on summative evaluation and potential recommendations for further institutionalization of this collaboratory approach.

\section{Results}

\subsection{Evolution and structure of the DIAUD Network}

The idea of greater involvement of the disability community into the processes of Habitat III emerged from a number of different quarters. Some of our previous work on Accessible Global Governance, done in conjunction with and supported by The Nippon Foundation [49], pointed to the need for enhanced participation of persons with disabilities in broad global governance processes. It specifically pointed to the need for the principled and strategic use of information and communication technologies (ICTs) to support this process, and both the Institute on Disability and Public Policy (IDPP) at American University in Washington, DC and The Nippon Foundation (TNF) wanted to apply these ideas to enhancing the policy efforts of the global disability community. In addition, the Department of Social Policy and Development (DSPD) at UNDESA, which also serves as the Secretariat for the Convention on the Rights of Persons with Disabilities (SCRPD), wanted to support greater disability content and the engagement of the disability community, into the important area of inclusive cities and urban environments. Fortunately, the kernel of this substantive work was already being done. Dr. Victor Pineda, based at the University of California, Berkeley, a globally recognized expert on inclusive cities, was trying to mobilize interest amongst the disability community in contributing to Habitat III.

6.1.1 Creation of the DIAUD Network. A "perfect storm" of events led to the creation of DIAUD. UNDESA/SCRPD took a leadership role suggesting the creation of a network of disability advocates who could contribute substantively to the Zero Draft of the Habitat III Outcome Document. They identified Dr. Pineda as a potential substantive leader of this network, and Dr. Derrick Cogburn, Director of IDPP as being willing to help support this network through his "policy collaboratory" approach. In close collaboration, the three of them, along with TNF, created a list of network members. UNDESA/SCRPD suggested the most appropriate mechanism for their involvement would be an informal multistakeholder network. As such, on May 2016, the informal Global Multistakeholder Network on Disability Inclusion and Accessible Urban Development (DIAUD) was born.

6.1.2 Organizational Composition of DIAUD. Initially, fifty-five (55) persons from around the world were appointed to the DIAUD Network by UNDESA. Importantly, Dr. Pineda became the de facto coordinator of the network, and Dr. Cogburn became the de facto coordinator of the policy collaboratory.

6.1.3 Types of Actors in the DIAUD Network. The initial DIAUD network included: UNDESA staff members; government officials; persons with disabilities; leaders of disabled persons organizations (DPOs); disability rights and urban development scholars; and foundations. Staff from Dr. Pineda's World Enabled Foundation and Dr. Cogburn's IDPP were appointed to support the DIAUD Network.

6.1.4 Regional Distribution in DIAUD. While many members of the network are located in New York, Washington, DC, and California, other regions of the world are also represented, including: Africa $(\mathrm{n}=1)$; Asia Pacific $(\mathrm{n}=12)$; Latin America $(\mathrm{n}=8)$; MENA $(n=3)$; Western Europe $(n=9)$; and North America $(\mathrm{n}=37)$. Countries represented include: Austria, Belgium, Costa Rica, Ecuador, Egypt, France, India, Indonesia, Italy, Japan, Norway, Philippines, Saudi Arabia, Switzerland, UAE, USA, and Vietnam.

6.1.5 Active Actors in DIAUD. Before the cyberinfrastructure for the policy collaboratory was established, all email communication was handled on an ad-hoc basis. Dr. Pineda started an email chain with the addresses of all the purported network members, as well as the support staff. Most people wanting to communicate with the network would simply "replyall" to that message and include their message and/or any attachments or links they wanted to send out to the entire network. At the forefront of these active members is Dr. Pineda, followed by network members in Ecuador and Indonesia.

6.1.6 Influential Actors in DIAUD. Some network members generate substantial discussion and responses to their messages. In addition to Dr. Pineda, IDPP program manager Robert Guerra animates the network, along with key postings from UNDESA staff members.

6.1.7 Structural Changes in DIAUD. There was a good deal of initial energy amongst the network. However, unlike some of the other networks UNDESA 
units support, there was no formal appointment letter to this network from DESA. As a result, some of the members "appointed" to the network, do not seem themselves as being members of the network at all. This was particularly the case with one high profile academic, who responded sharply to the survey invitation that while he definitely supported the aims of the initiative, he "had not agreed to be a member of this network, was not a member of the network, and did not have time to be a member of this network."

Thus, even though the period under review was very hectic, and with numerous critical deadlines were evident (such as deadlines to contribute to the Zero Draft of the Outcome Document; deadlines to submit side events, deadlines to register for the preparatory committee meetings, activity of the network was relatively low. However, as new drafts of the Outcome Document became available, along with deadlines for preparation for Habitat III, activity increased.

It is likely that the response rate to the survey indicates close to the actual level of membership in the DIAUD Network. If so, there are closer to 20 members, mostly from NGOs/civil society $(n=10)$, foundations $(n=3)$, universities $(n=2)$ and international organizations participating in the network.

\subsection{DIAUD as Transnational Advocacy Network}

Given that the DIAUD was initiated by UNDESA/SCRPD/DSPD, it has been shaped to a great degree by their organizational and substantive interests (in this case, their interest in disability inclusion in Habitat III). However, does this network reflect the broader concept of a transnational advocacy network? If so, it should reflect some of the key elements that make up a TAN, including shared values, common discourse, information exchange, and others.

6.2.1 Shared Values in DIAUD. There seems to be a high level of shared values amongst the DIAUD network. On the surface, the network has been created to focus on integrating disability content into the Habitat III processes. But what about deeper levels of policy agreement within the drafting of the shared documents?

One area of potential disagreement amongst the DIAUD network is the degree to which explicit statements about disability should be included in the Outcome Draft. Some network members seem to prefer an explicit reference and stand-alone paragraph on disability, whereas others prefer a more subtle approach. Nonetheless, on balance, there is a shared vision for disability inclusion in the New Urban Agenda within the DIAUD Network.
6.2.2 Does the DIAUD Network have a common discourse? While there is certainly unevenness amongst the network in terms of the depth of their knowledge about the issue, it appears the DIAUD Network members write about disability-inclusive urban development in a very similar way.

There are also similar experiences. All survey respondents had attended at least one UN conference, with $3 / 4$ having attended five or more. Comparable levels of participation were registered for non-UN international conferences. Most DIAUD Network members showed familiarity with processes and procedures at UN and non-UN international conferences, with over $95 \%$ saying that they were at least 'moderately knowledgeable' about both.

Additional insights into DIAUD's common discourse were provided also by open questions about the rationale behind members' participation in international conferences, which was driven most frequently by three shared interests, including: the implementation of the UN Sustainable Development Goals (SDGs) and people with disabilities; the CRPD; and accessible ICTs.

6.2.3 Information Exchange in DIAUD. In the short period since the network was formed, its members of the network have exchanged a substantial amount of information. This information includes a range of background information about Habitat I and II, and deadlines about the registration for Habitat III, submission of side events, and other information related to the Preparatory Committee meetings.

This marked a substantial increase in communication among network members. In a typical month, fewer than $20 \%$ of survey respondents said they communicated with other DIAUD members "frequently" through any channels, including face-toface, telephone, and web-based platforms. The only exception to this pattern was (non-DIAUD) email lists, which $77 \%$ of respondents used at least "sometimes" in a typical month to communicate with other network members. Document repositories and webconferencing were the second and third most popular communication methods as over $40 \%$ of respondents used each of them to connect with other DIAUD members during a typical month. In contrast, blogging, letters and faxes, traditional video-conferencing, as well as application sharing were the least popular methods of communication, as $70 \%$ of respondents never used any of these to connect with other DIAUD members.

6.2.4 Policy Influence in DIAUD. Influencing policy is a specific objective of the DIAUD Network. Even though Habitat II did include references to persons with disabilities, the initial drafts of the Outcome 
Document for Habitat III did not include references to persons with disabilities. One of the major drivers of the need to create the DIAUD Network was to coordinate a global response from amongst the disability community to the emerging drafts of the Outcome Document for Habitat III and the NUA.

Despite the high levels of familiarity with processes and procedures at both UN and non-UN international conferences mentioned above, only $46 \%$ and $53 \%$ of respondents felt at least 'very confident' about their ability to influence the outcome of each of these two types of forums.

6.2.5 Epistemic Communities and DIAUD. Our conceptual understanding suggests one important mechanism contributing to the effectiveness of a TAN is the degree to which it is linked to an epistemic community. An epistemic community is a scholarly community that has a relatively shared scientific paradigm, and is willing to engage with the policy process on the basis of this shared paradigm [50].

This is an area where our analysis of the DIAUD Network is inconclusive. While there are a substantial number of academics participating in the network, some-including the coordinator-with deep knowledge of the public policy issues related to disability inclusion in the New Urban Agenda, there are no explicit linkages to what would qualify as an epistemic community.

This shortfall could be particularly important for the long-term impact and sustainability of the network, so that its reliance only on a few knowledgeable network members is lessened.

\subsection{Collaboration Readiness in DIAUD Network.}

Previous research on scientific collaboratories has shown that one of the most important indicators of potential success of a collaboratory is 'collaboration readiness' $[51,52,53]$. This concept of Collaboration Readiness has three important dimensions: (1) Collaboration Orientation Readiness; (2) Collaboration Infrastructure Readiness; and (3) Collaboration Technology Readiness. In general, Collaboration Orientation refers to the willingness and desire on the part of participants in a collaboratory to work together. Collaboration Infrastructure readiness tries to identify the degree to which the network has some existing collaboration tools and techniques for collaboration. Finally, Collaboration Technology readiness tries to measure the degree to which the participants are experienced in various kinds of information and communication technologies. These skills could be utilized or built upon in the collaboratory, so preexisting skills are important predictors of success.
Based on our baseline data collection, particularly our survey, which contains items specifically measuring these three dimensions of collaboration readiness, the DIAUD Network has a high degree of collaboration readiness on all of these dimensions.

6.3.1 Communication Levels in DIAUD. In terms of collaboration orientation readiness, DIAUD members more frequently communicate with one another using email, web conferencing, and other virtual mechanisms compared to face-to-face interactions. This is to be expected due to the diversity of team members who are located in multiple countries around the world. While this could be seen as a challenge, $62 \%$ of members felt moderately or extremely confident in their ability to work with colleagues located in different parts of the world. Network members indicated they frequently (four or more times per year) met face to face with several key team members including Dr. Victor Pineda $(12.5 \%)$ and Dr. Cogburn (23\%). However, the majority of members met face to face one or less times per year. Conversely, a significant percentage of members communicated frequently via email. Based on these results, a comprehensive virtual platform will help enable DIAUD team members more effectively communicate and enhance the group's success.

6.3.2 Trust Levels in DIAUD. Trust is vital to healthy team dynamics and team performance, and is also critical to collaboration orientation readiness. Overall, DIAUD members have a high level of trust in general, with $87 \%$ believing that people can be trusted. Additionally, the study aimed to assess levels of social capital, essential in building trust within a group. The study showed that network members feel a sense of belonging from a variety of sources, with $75 \%$ feeling a sense of belonging from the people they work with. Further, group members overwhelmingly (87\%) prefer a leadership style that makes others feel at ease, and preferred a friendly and approachable style allowing all views to be heard, and $77 \%$ reported that a friendly and approachable style is the most prevalent in the DIAUD network. These facts are indicative of a high level of trust among team members and leadership.

6.3.3 Social Network Centrality in DIAUD. DIAUD members had unique relationships with one another prior to the formation of the network, and certain key members are likely communicate more frequently based on their job descriptions and positions. Key members are called upon for advice more frequently than others. Specifically, $92 \%$ of respondents said that they felt comfortable going to Dr. Pineda for advice, and $100 \%$ of respondents said they felt comfortable going to Ambassador Luis Gallegos. 
6.3.4 Leadership Alignment in DIAUD. One of the key concepts in the study, and one that contributes to our overall understanding of Collaboration Readiness, is what we call the level of Leadership Preference/Perception Alignment. This concept refers to the degree to which the stated preference for taskfocused leadership versus relationship-focused leadership is aligned with the perceived style of leadership within the network. Importantly, $92 \%$ of respondents somewhat or strongly agree that the group has an open relationship and can freely share ideas and feelings with the group, and $76 \%$ of respondents somewhat or strongly agree that they can talk freely about difficulties and know another group member will listen to them. While these statistics indicate that the team is predisposed to a relationship focused leadership style, only approximately half of the respondents $(53 \%)$ strongly agree or somewhat agree that they would feel a sense of loss if a team member left the network, which indicates that the group is also somewhat comfortable with a task focused leadership style. Understanding the network members' perception of the leadership is an important predictor of the group's ability to collaborate and work towards a shared vision. A significant amount of respondents believed leadership let members know what is expected of them most of the time or always, and $71 \%$ thought leadership tries out new ideas on the group. $75 \%$ of respondents believed network leadership were friendly and approachable, and more than half reportedly felt that group suggestions were validated and put into action. Furthermore, 91\% of respondents stated that leadership treats all group members equally.

6.3.5 Collaboration Technology Readiness. Moreover, the study showed that large portions of the group are very experienced or somewhat experienced in using document repositories (50\%), group calendaring (80\%) and webconferencing applications (64\%). This indicates that the group has the overall technical ability to collaborate, although improvements can be made.

Media preferences in information exchange in DIAUD did not appear to be immediately associated with technological expertise as correlation analysis found no noteworthy relationships between the most popular technologies in the network (email lists, document repositories, and webconferencing) and respondents' levels of experience with each of these. Indeed, accessibility is an important factor to consider when it comes to media preferences as several DIAUD members have disabilities and indicated utilizing assistive technologies at least weekly in the survey, including closed captioning $(30 \%)$ track ball mouse $(14 \%)$, oversized or dual monitors $(22 \%)$, screen readers $(7 \%)$, and voice input $(12.5 \%)$. Although all respondents indicated sufficient support for ICT needs, it is important to remember that with participation in a collaboratory such technology needs may increase.

\subsection{Collaboratory Use in the DIAUD Network.}

Although the DIAUD Network has operated for a relatively short period, it is possible to observe a series of emerging usage patterns in relation to the main collaboratory components. This sheds light on how the collaboratory infrastructure supported the establishment of the network and informs further strategic choices as DIAUD continues to strengthen and evolve. This section explores network use of the collaboratory resources, in each three components.

6.4.1 People-to-People DIAUD Use. Survey respondents were asked how confident they felt about their ability to work effectively with other network colleagues located around the world. Most respondents (over 60\%) indicated that they felt moderately or extremely competent, which suggested that they possessed at least a basic amount of information about other network members. As the DIAUD network continues to evolve, it is hoped that People-to-People resources such as photo directories and constituent relationship management services may boost levels of knowledge for the other respondents that did not feel as confident about their ability to collaborate with a geographically dispersed network. Occasional face-toface meetings, such as the one held in New York at UN Headquarters in June during the Conference of States Parties (COSP) to the CRPD may also help as $94 \%$ of respondents said these should occur at least some of the time in order to the network to operate effectively.

6.4.2 People-to-Resources DIAUD Use. As was noted above in the section on information exchange, document repositories were the most frequently used people-to-resources feature in the DIAUD network. Comparatively, resources such as blogs were much less popular and were never used by $87 \%$ of network members. This was despite the fact that only $50 \%$ of survey respondents indicated having at least some experience with document repositories compared to higher levels of experience with blogging.

6.4.3 People-to-Facilities DIAUD Use. Asynchronous forms of communication were more popular than synchronous. Email lists dominated as $77 \%$ of respondents had used them at least "sometimes" to interact with other network members. Comparatively, application sharing was particularly unpopular as $73 \%$ of survey respondents indicated that they never used this to interact with other members of the DIAUD 
network. Even more so, $80 \%$ of respondents said they never or very infrequently used instant messaging with network members. Surprisingly, most respondents indicated having at least some experience with application sharing (77\%) and instant messaging $(80 \%)$. At the same time, synchronous webconferencing was used at least sometimes $(40 \%)$.

6.4.4 DIAUD Network and Habitat III. Survey respondents placed great value in the DIAUD network and its ability to influence this process, with over $85 \%$ of respondents indicated that they thought the DIAUD network had been very to extremely effective in influencing the Quito declaration on Habitat III, with the remaining $15 \%$ believing the network had been at least moderately effective to this end. This optimism was not without merit. By 10 September 2016 at the conclusion of negotiations, the DIAUD Network had succeeded in getting 15 references to persons with disabilities into the Habitat III Outcome Document on the New Urban Agenda, including a stand-alone paragraph and a vision of the "right to the city" for all. Also, a proposal made by DIAUD for Persons with Disabilities to become the $16^{\text {th }}$ Partner Constituency Group (PCG) of the General Assembly of Partners (GAP) was accepted and the PWD-PCG was created, a network that will play an important role in Habitat III.

\section{Discussion}

This pilot project has enabled the participants in the Global Network on Disability Inclusion and Accessible Urban Development (DIAUD) to explore the potential of accessible cyberinfrastructure to enable persons with disabilities, the global disability community, and broader constituencies to participate in specific and complex global governance processes.

This study has helped to accomplish a number of important goals. We have been able to better understand the history of an important transnational civil society network, which we demonstrate is structured as a Transnational Advocacy Network [48].

We have also been able to highlight the problems of the DIAUD Network. While its stability has been remarkable, there have been so many contested issues within the DIAUD Network.

From this exploratory study, we have learned a great deal about the Global Network on Disability Inclusion and Accessible Urban Development. We see the DIAUD Network as a Transnational Advocacy Network that in spite of its shortcomings has been a surprisingly robust and effective mechanism for facilitating the global disability community's engagement in Habitat III.

\section{Recommendations}

The paper also points to a number of issues that the DIAUD Network might want to consider as it moves forward into the next phase of Habitat III and the postQuito implementation.

In our analysis we see a very small number of individuals and organizations playing a key role in creating the network, animating its activities, and facilitating the involvement of a diverse group of civil society actors from around the world to come together to participate in a new form of global multi-stakeholder participation in disability inclusive development. Before engaging with the DID Collaboratory, the members of the DIAUD Network relied almost solely on individual email and telephone conference calls to organize their work. The addition of the Drupal-based content management system helped strengthen information sharing within the network. The network leaders also recognized the need for additional technologies to assist with organizational features such as voting.

Based on this analysis, this study makes the following recommendations for the DIAUD Network, and for the ongoing development of the DID Collaboratory. Maintaining a linkage with DESA is critical to the impartiality and legitimacy of the network. Also, the role of network manager/facilitator is invaluable to the success of the network and should be maintained and supported. Weekly meetings, while viewed by some as excessive, have been critical to the rapid development and effectiveness of the network. Coordinators of the DIAUD Network put in place some tools to facilitate voting processes and "consensus calls," and these should be strengthened. There needs to be a greater focus on building the substantive knowledge of the network participants regarding Habitat III and inclusive cities. While this issue may seem obvious, the NUA is complex, and requires breadth and depth of substantive knowledge. In this regard, deepening the engagement with an academic/epistemic community would be helpful.

\section{Limitations}

While this study has demonstrated great utility, it does have limitations. One limitation is our own involvement in the DIAUD Network as participant observers. We are on the inside studying the network as a known member of the network. This gives us extraordinary access to the process, and to the participants, but we have also been required to maintain a strict focus on our objective analysis of the data, the participants, and the process. 


\section{References}

[1] Adler, N.J. "International Dimensions of Organizational Behavior", $4^{\text {th }}$. Ed. Cincinnati, OH: South-Western, 1997.

[2] Amant, K.S. "When cultures and computer collide: Rethinking computer-mediated communication according to international and intercultural communication expectations". Journal of Business and Technical Communication, 16 (2),2002, pp. 196-214.

[3] Carte, T., L. Chidambaram and A. Becker "Emergent leadership in self-managed virtual teams: A longitudinal study of concentrated and shared leadership behaviours" Group Decision and Negotiation, 15, 2006, pp.323-343.

[4] Cogburn, D.L. "Diversity matters, even at a distance: Evaluating the impact of computer-mediated communication on Civil Society participation in the World Summit on the Information Society", Information Technology and International Development, 1(4), 2005, pp.15-40.

[5] Daft, R.L.and R.H. Lengel ,"Organizational information requirements, media richness and structural design", Management Science, 32(5), 1986, pp. 554-571.

[6] Fischer, L. R., and K.B. Schaffer, "Older Volunteers". Newbury Park, CA, 1993.

[7] Hall, E. T., "Beyond culture”, Garden City, NJ: Anchor Books/Doubleday, 1976.

[8] Hofstede, G., "Culture's Consequences: International Differences in Work Related Values", Beverly Hills, CA: Sage, 1980.

[9] Holton, J.A. , "Building trust and collaboration in a virtual team", Team Performance Management, 7(3/4),2001, pp. 3647.

[10] Jarvenpaa, S.L.and D.E. Leidner, "Communication and trust in global virtual teams", Organization Science, 10 (6), 1999, pp.791-815.

[11] Joinson, A. N.,"Self-disclosure in computer-mediated communication: The role of self-awareness and visual anonymity," European Journal of Social Psychology, 31(2), 2001, pp.177-192.

[12] Kiesler, S. and L. Sproull, “ Group decision-making and communication technology", Organizational behavior and human decision processes, 52, 1992, pp. 96-123.

[13] Kingdon, J.W.,"Agendas, alternatives, and public policies”, NY: Addison-Wesley Longman, 1995.

[14] Kling, R., "Synergies and competition between life in cyberspace and face-to-face communities", Social science computer review, 14(1) (Spring), 1996, pp. 50-54.

[15] Krippendorf, K. "Content Analysis: An Introduction to its Methodology”, $2^{\text {nd }}$ ed. Thousand Oaks, CA: Sage, 2004.
[16] Lea, M. \& Spears, R."Computer-mediated communication, de-individuation and group decision-making", International Journal of Man-Machine Studies, 34, 1991, pp.283-301.

[17] Lee, O., "Cultural differences in e-mail use of virtual teams: A critical social theory perspective", Cyberpsychology \& Behavior, 5(3), 2002, pp. 227-232.

[18] Olaniran, B.A., "Group perfomance in computermediated and face-to-face communication media", Management Communication Quarterly, 7, 1994,pp. 256-281.

[19] Neuendorf, K. A., The Content Analysis Guidebook. Thousand Oaks, CA: Sage, 2002.

[20] Olaniran, B.A., "The effects of computer-mediated communication on transculturalism". In V.H. Milhouse, M.K. Asante, \& P.O. Nwosu (eds.) Transcultural Realities: Interdisciplinary Perspectives on Cross-Cultural Relations. Thousand Oaks, CA: Sage, 2001, pp. 55-70.

[21] Pekerti, A.A. and D.C.Thomas. "Communication in intercultural interaction: An empirical investigation of idiocentric and sociocentric communication styles", Journal of Cross-Cultural Psychology, 34(2), 2003 pp. 139-154.

[22] Powell, A., G. Piccoli and B. Ives, "Virtual teams: A review of current literature and directions for future research", Database for Advances in Information Systems, 35(1), 2004, pp. 6-36.

[23] Setlock, L.D., Fussell, S.R. \& Neuwirth, C. "Taking it out of context: Collaborating within and across cultures in face-toface settings and via instant messaging. Proceedings of CSCW, "NY: ACM Press, 2004.

[24] Shachaf, P. "Cultural diversity and information and communication technology impacts on global virtual teams: An exploratory study. " Information \& Management, 45(2), 2008, pp.131-142.

[25] Sia, C.L,Tan, B.C.Y \& Wei, K.K. "Group Polarization and Computer-Mediated Communication: Effects of Communication Cues, Social Presence, and Anonymity," Information Systems Research, 13(1), 2002, pp. 70-90.

[26] Sudweeks, F., and Simoff, S.J. "Leading Conversations: Communication Behaviors of Emergent Leaders in Virtual Teams." Proceedings of the 38th Hawaii International Conference on System Sciences, 2005, pp. 1-10, Hawaii, USA. [27] Ting-Toomey, S. "Communicating Across Cultures." New York: Guilford, 1999.

[28] Trompenaars, F. \& Hampden-Turner, C. "Building Cross-Cultural Competence: How to Create Wealth from Conflicting Values," New Haven: Yale University Press, 2000. 
[29] Walsh, J.P., Kucker, S., Maloney, N.C. \& Gabbay, S. "Connecting minds: Computer-mediated communication and scientific work." Journal of the American Society for Information Science, 51(4), 2000, pp.1295-1304.

[30] Walther, J. , Loh, T. \& Granka, L. "Let Me Count the Ways: The Interchange of Verbal and Nonverbal Cues in Computer-Mediated and Face-to-Face Affinity," Journal of Language and Social Psychology, 24(1), 2005, pp. 36-65.

[31] Wang, K.Y. \& Clegg, S. Trust and decision making: Are managers different in the People's Republic of China and in Australia? Cross Cultural Management, 9(1), 2002, 30-46.

[32] Weber, R.P. Basic Content Analysis, $2^{\text {nd }}$ ed. Newbury Park, CA: Sage Publications, 1990.

[33] Yoo, Y. \& M. Alavi. "Emergent Leadership in Virtual Teams: What Do Emergent Leaders Do?" Information and Organization, 14, 2004, pp.27-58.

[34] Zakaria, N. \& Derrick, C.L. Context-dependent vs. content-dependent: An exploration of the cultural behavioural patterns of online intercultural communication using e-mail, International Journal of Business and System Research, 4(3), 2010, pp.330-347.

[35] Ellis, J., Arnone, M., Cogburn, D. and Levinson, N., "Evaluating the Role of Face-to-Face Residencies in CrossNational, Accessible Cyberlearning", Proceedings of the $47^{\text {th }}$ Annual Hawaii International Conference on Systems Sciences, 2014.

[36] Atkins, D. E., Droegemeier, K. K., Feldman, S. I., Garcia-Molina, H., Klein, M. L., Messerschmitt, D. G., Messina, P., Ostriker, J. P., \& Wright, M. H. (2003). Revolutionizing science and engineering through cyberinfrastructure: Report of the blue-ribbon advisory panel on cyberinfrastructure. Washington, DC: National Science Foundation.

[37] Blanck, P., Hill, E., Siegel, C.D., \& Waterstone, M. (2004). Disability civil rights law and policy. St. Paul, MN: Thomson/West Publishers.

[38] Cogburn, D.L. \& Kurup, D.R. (2006, April 13). Tech U: The world is our campus. Network Computing, pp. 57-63.

[39] Cogburn, D.L. (2005). Partners or pawns? The impact of elite decision-making and epistemic communities in global information policy on developing countries and transnational civil society. Knowledge, Technology \& Policy, 18(2), pp. $52-82$.
[40] Cogburn, D.L. (2003). HCI in the developing world: What's in it for everyone? Interactions, 10(2), pp. 80-87.

[41] Finholt. T. (2002a) Collaboratories: Science Over the Internet. AAAS Science and Technology Yearbook (pp. 339344). Washington, D.C.: American Association for the Advancement of Science.

[42] Finholt, T. (2002b) Collaboratories. Annual Review of Information Science and Technology (pp. 74-107), 36. Washington, D.C.: American Society for Information Science

[43] Handel, M. \& Herbsleb, J.D. (2002) What is Chat Doing in the Workplace? ACM Proceedings of the ACM Conference on Computer Supported Cooperative Work CSCW'02, November 16-20, 2002, New Orleans, Louisiana, USA. ACM 1-58113-560-2/02/0011...\$

[44] National Academy of Science. (1993). National Collaboratories: Applying Information Technology for Scientific Research, Computer Science and

Telecommunications Board, National Academies Press.

[45] National Telecommunications and Information Agency. (1999). Falling through the net: Defining the digital divide.

[46] Olson, G.M., Atkins, D.E., Clauer, R., Finholt, T.A., Jahanian, F. Killeen, T.L., Prakash, A., Weymouth, T. (1998, May-June). The Upper Atmospheric Research Collaboratory. Interactions, pp 48-55.

[47] World Health Organization, "World report on disability", Geneva, 2011.

[48] Activists Beyond Borders. Keck and Sikkink, 1998.

[49] Accessibility in Global Governance: The (In)visibility of Persons with Disabilities. Derrick Cogburn (2016).

[50] Adler, E. \& Haas, P. M. (1992). Epistemic communities, world order, and the creation of a reflective research program. International Organization, 46, 367-390.

[51] Olson, G.M. and Olson, J.S. (2000), 'Distance Matters', Human-Computer Interac-tion, 15, pp. 139-179.

[52] Olson, G.M., Finholt, T.A. and Teasley, S.D. (2000), 'Behavioral Aspects of Collaboratories', in S.H. Koslow and M.F. Huerta (eds.), Electronic Collaboration in Science, Mahwah, NJ: Lawrence Erlbaum Associates, pp. 1-14.

[53] Olson, G.M., Teasley, S., Bietz, M.J. and Cogburn, D.L. (2002), Collaboratories to support distributed science: The example of international HIV/AIDS Research. 